\title{
Violência doméstica contra a mulher: uma revisão de literatura
}

\author{
Domestic violence against women: a literature review
}

\section{Gabriel Licoski dos Santos', Angélica Eckert Govoni', Henrique Borba Bittencourt', Jaqueline Batista da Silva ${ }^{4}$ e Renata Isabel Fedrizzi}

Resumo: $\bigcirc$ presente artigo teve como finalidade identificar através da literatura os processos que contribuem para a manutenção da violência doméstica na sociedade contemporânea. Para tal, foi realizada uma revisão de literatura narrativa utilizando as bases de dados, Lilacs, Pepsic, Scielo e Pubmed e dos descritores sobre saúde pública, violência doméstica e relações familiares. A literatura selecionada aponta para diversos fatores que estão relacionados à perpetuação da violência doméstica sendo eles: a construção dos papéis de gênero, a naturalização desse fenômeno, as crenças populares e a falta de preparo por parte dos profissionais da saúde. Nesse sentido, constatou-se a necessidade de ações de capacitação profissional para atender tal público, que atuem na desnaturalização da violência doméstica e que permitam a ressignificação social deste processo.

Palavras-chave: Saúde pública; Violência doméstica; Relações familiares.
Abstract: The purpose of this article was to identify through literature the processes that contribute to the maintenance of domestic violence in contemporary society. For this purpose, a narrative literature review was carried out using the databases, Lilacs, Pepsic, Scielo and Pubmed and the key words public health, domestic violence and family relationships. The studies selected point out several factors related to the perpetuation of domestic violence such as: the construction of gender roles, naturalization of this phenomenon, popular beliefs and lack of preparation by health professionals. In this regard, it was observed the need for professional qualification actions to serve such public, which act in the denaturalization of domestic violence and allow for the social resignification of this process.

Keywords: Public health; Domestic violence; Family relationships.

\footnotetext{
1 Estudante de Psicologia. Membro da SPRGS. E-mail: biellicoski@gmail.com

2 Psicóloga. Membro da SPRGS. E-mail: angelicagovoni@hotmail.com

3 Psicólogo. Membro efetivo da SPRGS. Psicanalista em Formação da Sigmund Freud Associação Psicanalítica. E-mail: iqueb2@ gmail.com

4 Estudante de Psicologia. Membro da SPRGS. E-mail: jackbatistsilva@gmail.com

${ }_{5}^{5}$ Psicóloga. Membro efetivo da SPRGS. Psicanalista em formação da Sigmund Freud Associação Psicanalítica. E-mail: renataisabelfedrizzi@gmail.com
} 


\section{Introdução}

0 presente artigo foi proposto a partir do interesse da Liga de Estudantes e Recém-formados (L.E.R) da Sociedade de Psicologia do Rio Grande do Sul em explorar a temática da violência doméstica (VD). A escolha por este conteúdo de estudo surgiu a partir dos encontros e discussões semanais do grupo, que resultou na organização e realização do evento "Isolamento social e e violência contra a mulher: quando ficar em casa se torna uma ameaça" com o intuito de ampliar conhecimentos sobre 0 tema, estimular e sensibilizar a sociedade e os participantes do mesmo em se implicar sobre o fenômeno da violência doméstica no contexto pandêmico.

A VD é um fenômeno social multifatorial, que vem apresentando um aumento significativo no número de casos, sobretudo durante a realidade de isolamento social instaurado, devido ao cenário atual da pandemia de COVID-19 (Marques, Moraes, Hasselmann, Deslandes \& Reichenheim, 2020). Segundo o Fórum Brasileiro de Segurança Pública de 2020, as medidas de distanciamento contribuíram para que as mulheres fossem compelidas a permanecer por maior tempo na presença de seus agressores, o que pode intensificar a VD.

Além disso, segundo relatório do Poder Judiciário do Estado de Santa Catarina, referente aos meses de janeiro a março de 2020, anteriores a pandemia, constatou-se que nos Tribunais de Justiça (TJs) de São Paulo (12,42\%), Santa Catarina (10,46\%) e Maranhão (9,16\%), houve um maior números de casos registrados de solicitações por medidas protetivas emergenciais deste mesmo período em relação ao ano passado, 2019.

Para a Organização Pan-Americana de Saúde (OPAS) o fenômeno da VD é visto como um problema de saúde pública que fere seriamente os direitos humanos e é mais direcionado às mulheres (OPAS, 2017). Porém, apesar de serem a parcela da população mais afetada por esse fenômeno, este atinge também, direta ou indiretamente, outras pessoas que integram o grupo familiar. Nesse sentido, cabe destacar que grupos como a população idosa e infanto juvenil também são frequentemente vítimas de VD (Barros \& Freitas, 2015; Martins \& Nascimento, 2017).

A VD está presente no mundo inteiro, ainda que em intensidades diferentes, sendo muitas vezes reforçada e velada por padrões culturais. Em vista disso, a Organização Mundial da Saúde (OMS) criou em 2020 a campanha \#SafeHome, ou na tradução \#casasegura, como uma forma de oferecer apoio às vítimas de violência. Estudos revelaram que mais de 1 bilhão de crianças e adolescentes entre 2 e 17 anos passaram por algum tipo de agressão no ambiente familiar no ano de 2019 (Organização das Nações Unidas, 2020).

Com base no exposto, percebemos a relevância de tal temática devido a sua alta prevalência e seus impactos na sociedade. Nessa perspectiva, este artigo surgiu com o intento de identificar através da literatura os processos de manutenção e perpetuaç̧ão da VD na sociedade contemporânea. Para isto, objetivou-se explorar o conceito de VD e suas tipologias, analisar os processos sócio-histórico-culturais que contribuem para a objetificação do sujeito e as formas que a rede de atendimento tem acolhido os envolvidos em casos deVD.

\section{Método}

A metodologia escolhida para o presente artigo foi a revisão de literatura narrativa. Para a realização desta revisão, foram selecionados artigos contendo os seguintes descritores: saúde pública, violência doméstica, relaç̃ões familiares e seus respectivos correspondentes em inglês e espanhol nas bases de dados: Lilacs, Pepsic, Scielo e Pubmed. Os critérios de inclusão utilizados neste estudo foram publicações com o conteúdo disponível na íntegra mediante suporte eletrônico, estar disponível em português, espanhol ou inglês, englobar pelo menos dois dos descritores selecionados e data de publicação ser entre 2015 e 2020 .

Após a leitura dos títulos e resumos, foram excluídos os que se encontravam repetidos e os que apresentaram inadequação quanto à temática escolhida. Por fim, foram selecionados aqueles que compuseram o corpus de análise do presente artigo, totalizando 58 artigos. Para além dos documentos já citados, foram selecionados livros e materiais diversos anteriores às datas previamente estabelecidas com a finalidade de corroborar com a discussão sobre a temática. A seguir serão apresentados os dados coletados, estes foram divididos nos seguintes segmentos: a história da VD, conceitos e tipos deVD, a influência dos papéis sociais e por fim a rede de atendimento.

\section{A história da violência doméstica}

AVD caracteriza-se como uma manifestação social, um fenômeno profundo e complexo, pois atravessa o que émais valioso ao ser humano, o direito à vida. Destacando que tais atos comprometem direitos fundamentais que são garantidos a todos por lei como saúde, respeito à liberdade e a dignidade humana (World Health Organization, 2016).

Minayo (1998) descreve a violência como um acontecimento representado por atos executados por indivíduos, grupos de diversas classes sociais e governos, que resultam em danos físicos, emocionais e morais. A violência é uma via que ignora o diálogo, não perpassa o respeito e a humanização. Ela está associada ao desejo do agressor de controlar e extinguir o outro, exterminando sua subjetividade ao tentar modificá-lo para torná-lo igual ou semelhante a si (Jacinto, 2018).

Segundo Castells (1999), o valor da imagem masculina, em primazia a imagem da mulher, émodelo da sociedade machista, que governa nas relações sociais, no coletivo e no exemplo de família convencional tradicionalmente descrita pela cultura. Modelo este patriarcal, determinado pelo poder do homem sobre a mulher e os filhos, uma base pela qual diversas sociedades modernas estão construídas.

As relações de excesso, submissão e coerção das mulheres foram constantemente motivo de interesse e dedicação de estudos dos movimentos feministas. 0 argumento da opressão contra a mulher, até então silenciada e restrita, passou a ganhar visibilidade na década de 60 com tais movimentos em favor do público feminino. No Brasil, estas manifestações ganharam força na década de 80 e expressaram-se como problemática pública de saúde nos anos 90 (Vieira et al., 2003).

Pedro (2005) aponta para os avanços proporcionados pelo movimento feminista, como a entrada da mulher no mercado de trabalho, a realização de estudos acadêmicos e a inclusão em movimentos sociais. A partir disso, foi possível uma maior inserção desta categoria de gênero em diferentes contextos e assim a violência tomou outro rumo, não sendo vista apenas diferenças biológicas, mas como resultado de representaçôes sociais.

Neste sentido, estes movimentos na década de 80, reivindicaram 0 posicionamento do Governo com investimentos em políticas públicas que 
abarcasse também questões de gênero. Surgindo assim os primeiros serviços específicos para atenção a mulheres em situação de violência: em 1984, os Centros de Orientação Jurídica e Encaminhamento e em 1985, a Delegacia Especial de Atendimento às Mulheres (D'oliveira e Schraiber, 2013).

Em 2006 é publicada a Lei n. 11.340, nos termos do $8^{\circ}$ parágrafo do art. 226, a Lei Maria da Penha, que traz mecanismos para frear atos de violência doméstica e familiar, além de caracterizar como crime, a lei prevê a necessidade do entendimento dos serviços e a capacitação dos profissionais que atuam em questões de gênero e etnia (Brasil, 2006). Além disso, reconhecer condutas contra a mulher como problema de saúde pública e não somente como questões jurídicas e de segurança é primordial para caracterizar os casos e para planejamento de estratégias de ação, como os serviços de Atenção Primária à Saúde (APS) assumem importante papel através da Estratégia de Saúde da Família (Dóliveira e Schraiber, 2013).

As ações de agressão estão presentes nas mais variadas circunstâncias, seja em relação à etnia, gênero ou grupo social. Frequentemente, tais atos passam despercebidos e por vezes são classificados como drama, o que agrava este tipo de violência. Esses atos executados contra a mulher são em sua maioria perpetrados pelo parceiro íntimo, ou ex-parceiro e quase sempre ocorrem no ambiente familiar (Schraiber et al., 2009).

\section{Conceitualização e tipos de violência doméstica}

0 conceito de violência de acordo com Bittencourt e Santos (2019) é diverso e está se transformando de forma contínua ao longo do tempo, sendo movido principalmente pelas mudanças nos papéis sociais e de classe. Entretanto, apesar das transformações conceituais, a tipologia do fenômeno em si continua presente, sendo muitas vezes velada por seus atores sociais, os mesmos que deveriam ser vetores de mudança dessa problemática social.

A resolução 49.25 da OMS de 1996, classifica a violência como fator central na problemática quando se fala em saúde pública. Demandou-se a OMS que elaborasse uma tipologia que definisse os tipos de violência, bem como os vínculos entre eles. A tipologia proposta indica três grandes categorias de violência: auto infligida, interpessoal e infligida por parceiro íntimo, que correspondem às características daquele que comete 0 ato violento.

Neste estudo o foco será na categoria tipológica da violência interpessoal infligida por meio da VD. Esta é apresentada por Martins e Nascimento (2017) como um delimitante da esfera privada, a qual dá ênfase a uma esfera da vida independentemente do sujeito, do objeto ou do vetor da ação, que segundo os autores pode gerar consequências abrangentes com diferentes repercussões para as vítimas. Por exemplo, pessoas que sofreram esses abusos têm, em média, mais problemas de saúde do que as que não sofreram tanto em relação ao funcionamento físico, quanto ao bem-estar psicológico.

A VD se manifesta caracteristicamente por meio da agressão física, sexual, psicológica, patrimonial e/ou moral (Sapkota, Bhattarai, Baral \& Pokhare, 2016; Martins \& Nascimento, 2017). De acordo com os autores, as principais representações afligidas por esse fenômeno são mulheres e crianças, sobretudo em famílias de baixa renda, pouca escolaridade e com histórico de abuso de substâncias. Porém, isso não exclui a manifestação desse fenômeno sobre a população idosa, a adolescente, de Lésbicas, Gays, Bissexuais, Trans, Queer, Intersexuais e Assexuais (LGBTQIA+), dentre outros (Martins \& Nascimento, 2017).
Devido a predominância histórica dos casos de VD ser praticado contra mulheres em âmbito global como apontado por Bartolomei (2015), muitas das legislações existentes norteiam a temática com enfoque na violência acometida contra estas. No Brasil em relação às diversas formas de manifestação de VD supracitadas, temos como parâmetro norteador o direcionamento aferido pelo 0 art. 70 da Lei n 11.340 de 07 de Agosto de 2006 (Lei Maria da Penha) o qual entende por formas de VD e familiar contra a mulher a:

I - a violência física, entendida como qualquer conduta que ofenda sua integridade ou saúde corporal;

II - a violência psicológica, entendida como qualquer conduta que Ihe cause dano emocional e diminuição da autoestima ou que the prejudique e perturbe o pleno desenvolvimento ou que vise degradar ou controlar suas ações, comportamentos, crenças e decisões, mediante ameaça, constrangimento, humilhação, manipulação, isolamento, vigilância constante, perseguição contumaz, insulto, chantagem, violação de sua intimidade, ridicularização, exploração e limitação do direito de ir e vir ou qualquer outro meio que the cause prejuízo à saúde psicológica e à autodeterminação;

III - a violência sexual, entendida como qualquer conduta que a constranja a presenciar, a manter ou a participar de relação sexual não desejada, mediante intimidação, ameaça, coação ou uso da força; que a induza a comercializar ou a utilizar, de qualquer modo, a sua sexualidade, que a impeça de usar qualquer método contraceptivo ou que a force ao matrimônio, à gravidez, ao aborto ou à prostituição, mediante coação, chantagem, suborno ou manipulação; ou que limite ou anule o exercício de seus direitos sexuais e reprodutivos;

IV - a violência patrimonial, entendida como qualquer conduta que configure retenção, subtração, destruição parcial ou total de seus objetos, instrumentos de trabalho, documentos pessoais, bens, valores e direitos ou recursos econômicos, incluindo os destinados a satisfazer suas necessidades;

V - a violência moral, entendida como qualquer conduta que configure calúnia, difamação ou injúria.

(Lei no 11.340, 2006)

Assim, a partir das pontuações levantadas a respeito desse fenômeno global, se faz necessário seguir como as questões de subordinação de gênero e papéis sociais a fim de alcançar uma compreensão maior sobre o processo sócio-histórico que envolve e perpetua a VD mesmo em tempos de ampla difusão dos direitos humanos (Santos \& Witeck, 2016). 


\section{Os papéis sociais}

Ao nos aprofundarmos na questão da VD torna-se imprescindível tratarmos também das relações de poder estruturantes da sociedade. Para Foucault (2014), a sexualidade é como um dispositivo que através do discurso atua como base na produção das identidades dos sujeitos, definindo o que cabe ao masculino e feminino. Nesse âmbito, observam-se valores e rituais sociais que criam e tendem a manter um sistema em que as mulheres aderem ao discurso predominante e por consequência ao papel de submissão Assim, estas relações podem tanto ser utilizadas com a intenção manter 0 estado atual quanto com a finalidade de alterar tal conjectura.

Nesse cenário, a violência contra a mulher surge como uma manifestação deste sistema de dominação. Tendo em vista que a ideologia por si só não é suficiente para garantir a obediência da vítima se realiza o uso da violência física com a finalidade de coagi-las a submissão. Esta se apresenta para aqueles inseridos nestas relações como algo natural e dessa maneira a subordinação aparece como parte essencial desse processo. Portanto, a dominação pode ser vista como uma forma de violência simbólica já que se institui, principalmente, pela adesão do dominado ao detentor de poder e ao seu domínio (Bourdieu, 2019).

Partindo do exposto é possível constatar que o patriarcado auxilia na manutenção dessas estruturas de dominação, que se fazem ou fizeram presentes e legitimadas culturalmente pelas mais diversas instituições. Podemos citar, por exemplo, a visão da mulher enquanto propriedade do marido que por muito tempo esteve presente juridicamente em diversos páses e ainda o é em outros, ou ainda, as diversas propagandas que reforçam um determinado lugar que homens e mulheres devem ocupar. Dessa forma, 0 Estado, suas instituições e a própria sociedade agem para regular as práticas do que cabe a cada sujeito sendo na lógica patriarcal heteronormativa reforçado o papel passivo e submisso da mulher (Azevedo, 2017).

É nessa conjuntura que o modelo familiar acaba por reproduzir tal desigualdade resultante das expectativas sobre 0 comportamento de homens e mulheres. Isto posto, espera-se do gênero feminino sensibilidade, passividade, obediência, delicadeza, o cuidado e, principalmente, a subordinação, enquanto ao gênero masculino é conferido o papel de provedor, forte, dominador que não pode demonstrar suas fraquezas. Nesse quadro, o homem évalorizado em detrimento da mulher tendo seu poder sobre o corpo desta legitimado pela estrutura social o que abre espaço ao sentimento de posse (Pereira-Gomes et al., 2015).

Cabe ressaltar que tal fenômeno não é exclusivo entre casais hétero, mas é neste tipo de relaçã̃o que a maioria dos estudos encontrados nesta revisão bibliográfica voltaram seu foco. Ademais, é importante compreender que a violência no âmbito doméstico não tem relação direta com as diferenças anatômicas e sim com questões referentes aos papéis de gênero, classe econômica, étnicas e raciais (Cezario, 2015).

Ademais, no estudo de Jesus e Sobral (2017) é evidenciado que na Delegacia Especializada da Mulher de Centro de Teresina/PI se encontra presente a utilização de estereótipos que diminuem e culpam as mulheres ao se referir aos atos destas como provocativos e motivadores para aVD. Desta forma, são validadas as desigualdades de gênero e estes acabam defendendo o domínio patriarcal em que a sociedade está inserida.

Ainda, com base neste mesmo estudo, a mulher évista como a principal responsável desta violência e não como uma vítima. Seguindo esta lógica, ela provoca os homens e descumpre seu papel de mulher, esposa e mãe, que, quando denuncia, coopera com a violência e assume o papel de vítima e não como um sujeito na relação. Esse lugar de vítima, ainda é rotulado como um objetivo de ter ganhos financeiros ou patrimoniais, ou ainda para intimidar os homens.

\section{A rede de atendimento}

A Atenção Primária à Saúde é um serviço que oferece cuidado às mulheres em situação de VD, tendo em vista que se trata de uma questão de saúde pública (d'Oliveira et al., 2020). Segundo Sagot e Carcedo (2000) citado por d'Oliveira et al. (2020) a APS é considerada a porta de entrada do sistema de saúde e um dos primeiros serviços buscados quando há necessidade de assistência. Os autores apontam que ela é um serviço com atuação voltada à família e a território no qual se insere. Além disso, tem como práticas, intervir com ações de prevenção e promoção da saúde, ofertar assistência de forma contínua às mulheres, independente da presença de patologias, o que leva a busca do serviço mesmo na ausência de adoecimentos (d'Oliveira et al., 2020).

0 atendimento às mulheres vítimas de VD deve ocorrer de maneira ética e respeitosa conforme prevê 0 Sistema Único de Saúde (SUS) (Nascimento et al., 2019). Neste sentido, podem ser percebidos alguns facilitadores na APS para ampliar o cuidado dessas mulheres, como ser um local de maior visibilidade e primeiro acolhimento e de possibilidade de receber os devidos encaminhamentos. Ademais, o princípio da integralidade, a ideia de saúde como direito, às visitas domiciliares, 0 acolhimento e o Projeto Terapêutico Singular - definido por Brasil (2009) como "um conjunto de propostas e de condutas terapêuticas articuladas, para um sujeito individual ou coletivo, resultado da discussão de uma equipe interdisciplinar" - foram apontados como pontos positivos para este cuidado (d'Oliveira et al., 2020).

Há também pontos que são considerados como obstáculos para que 0 cuidado seja efetivo. Tais como estrutura do trabalho em saúde relacionados com tempo, protocolos, falta de segurança, de fluxos claros, de capacitação, de trabalho em equipe e de reconhecimento da rede intersetorial, e ainda, a redução das necessidades de saúde às patologias (d'Oliveira et al., 2020).

Em estudo realizado por Nascimento et al. (2019) com Estratégias de Saúde da Família (ESF) localizadas em um município do Mato Grosso, foram levantadas algumas informações sobre como estes serviços têm atuado com situaçães deVD. Aidentificação dos casos pelos profissionais se mostrou como um entrave, tendo em vista a invisibilidade de notificação de violência e o pouco conhecimento dos mesmos em relação à abordagem e direcionamentos das mulheres. A falta de experiência profissional e curricular é considerada como mais uma adversidade para 0 acolhimento e acompanhamento das vítimas, o que leva muitas vezes ao subregistro de casos. Ainda, é comum ao surgir a demanda, os profissionais realizarem encaminhamento para serviç̧os de referências antes mesmo do primeiro contato (Nascimento et al., 2019).

Outro estudo realizado com ESF's urbanas e rurais no município de Rio Grande no Rio Grande do Sul realizado por Broch et al. (2017) mostrou que a violência contra a mulher é uma realidade vivenciada tanto no trabalho como na vida pessoal. Por ser uma questão que está atrelada a características histórico-culturais de gênero tais particularidades muitas vezes interferem no cuidado das vítimas. AVD pode estar presente tanto nos centros urbanos como rurais, exigindo dos profissionais de saúde que ofereçam assistência integral a essas mulheres, livre de crenças e opiniões que possam influenciar o cuidado (Broch et al., 2017). 
Uma investigação realizada no Rio Grande do Sul analisou notificações de violência contra mulheres realizadas no período de 2010 ao primeiro semestre de 2014. A partir dos dados levantados, evidenciou-se que a maioria dos atendimentos em saúde recebidos pelas vítimas de VD foram realizados em ambulatório e as mesmas recebiam alta após os procedimentos realizados. Dentre os casos que sofreram abuso sexual, somente em 2,4\% foi realizada a profilaxia para HIV e outras ISTs. Este dado pode levar a pensar que existe um desconhecimento por parte dos profissionais acerca dos encaminhamentos que são recomendados nestes tipos de casos, que visem a redução dos agravos e dos danos à saúde (Lawrenz et al., 2018).

No que diz respeito aos encaminhamentos para a rede de proteção, 0 mesmo estudo citado no parágrafo anterior apontou que em sua maioria foram direcionadas à delegacia. Isso pode ser explicado pelo fato de que na maior parte das cidades do Rio Grande do Sul não existe Delegacia Especializada de Atendimento À Mulher (DEAMs), unidades especializadas da Polícia Civil em casos de VD. Demais casos foram encaminhados ao Centro de Referência da Mulher, Conselho Tutelar, entre outros. Essa diversidade de encaminhamentos pode explicitar uma falta de organização e de fluxos da rede de saúde e proteção, tendo em vista que a delegacia deveria ser a porta de entrada dos cuidados às vítimas de violência contra mulher (Lawrenz et al., 2018).

Por outro lado, pensando nas ações relacionadas a VD e na intervenção junto ao autor da violência, o estado de Minas Gerais conta com quatro programas neste sentido: Programa de Educação e Responsabilização para Homens Autores de Violência Doméstica contra a Mulher na Comarca de Pouso Alegre/MG (PERH); Projeto Dialogar - DEAM/Polícia Civil do Estado de Minas Gerais; Projeto Laços - ONG ABAN - Associação dos Amigos e Programa ANDROS - Homens Gestando Alternativas para o Fim da Violência - ONG Instituto ALBAM (Bernardes \& Mayorga 2017).

Ponce Antezana (2011) citado por Bernardes e Mayorga (2017) aponta controvérsias em relação a atuação junto ao agressor, como a utilização das verbas que deveriam ser destinadas às mulheres, ser desnecessário prender ou punir os agressores, mas usar formas para coibir o que foi feito, as ações são vistas como ineficazes, pois são considerados como adoecidos e não responsáveis pelas atitudes ou ainda acreditam que os programas não surtem efeitos, embasados em resultados insatisfatórios e de pouco alcance. No entanto, o mesmo autor mostra a importância dessa prática, que tem a finalidade de intervir junto ao agressor para quebrar a perpetuação da violência nos relacionamentos.

\section{Considerações finais}

Através desta investigação, foi possível por meio da análise da literatura, investigar o conceito de VD, sua construção histórica, como os papéis sociais contribuem para tal cenário e o funcionamento das redes de atendimento. Com base em tais dados, foi possível constatar a relevância da temática devido a sua alta prevalência, seus impactos as vítimas, a amplitude de concepções englobadas dentro do conceito de VD, que existem diversas formas e expressões deVD, que os papéis de gênero construídos historicamente acabam contribuindo para a adesão das vítimas a tais processos e que ainda há problemas envoltos na rede de apoio às vítimas de VD como a falta de capacitação dos profissionais.

Diante do exposto, percebemos a importância de investigações sobre a temática tendo em vista que auxiliam na divulgação das questões envolvidas na VD e na desnaturalização da mesma. Nessa perspectiva, através da identificação dos mecanismos envoltos no processo de perpetuação da VD percebe-se que este é labiríntico envolvendo diversos fatores que se inter relacionam e contribuem para a continuidade de tal fenômeno. Assim, também os processos envoltos em seu desmonte são difíceis visto que a VD é normatizada e perpetrada sócio-historicamente ao longo dos séculos já que está ligada às estruturas de dominação sobre o corpo feminino.

Dessa forma, visto que os profissionais que prestam atendimento às vítimas de VD estão também inseridos nesta sociedade patriarcal, observa-se a necessidade de ações com a finalidade de capacitar/atualizar os mesmos e sobre como proceder no atendimento com as vítimas, assim como medidas de conscientização geral da população considerando a subnotificação apontada e os ditos de senso comum sobre o tema. Assim, discutindo e refletindo sobre a questão da VD, podemos ir além de uma visão simplista e determinista vendo esta em sua complexidade e completude. Consequentemente, tais debates possibilitam a ressignificação desta problemática e dos autores envolvidos visando a atenuação dos mecanismos envolvidos na perpetuação da VD.

\section{Referências}

Azevedo, F. M. C. (2017). 0 conceito de patriarcado nas análises teóricas das ciências sociais: uma contribuição feminista. Rev. Três Pontos Dossiê Múltiplos Olhares sobre Gênero. 12-20. Recuperado em: https://periodicos. ufmg.br/index.php/revistatrespontos/article/view/3386

Barros, A. S.; Freitas, M. F. Q. (2015). Violência doméstica contra crianças e adolescentes: consequências e estratégias de prevenção com pais agressores. Pensando Famílias, 19(2), dez. 2015, (102-114). Recuperado em: http://pepsic.bvsalud.org/pdf/penf/v19n2/v19n2a09.pdf.

Bartolomei, M. R. (2015). Domestic violence and human rights: An anthropological view. Ex aequo, (31), 91-104. Recuperado em: http://www.scielo.mec.pt/scielo.php?script=sci_arttext\&pi$d=$ S0874-55602015000100008\&lng=pt\&tIng=es.

Bernardes, J. P. \& Mayorga, C. (2017). Um estudo sobre intervenções junto a homens autores de violência doméstica contra mulheres. Revista de Psicología, 26(1), 1-15. Recuperado em: https://scielo.conicyt.cl/scielo. php?pid=S0719-05812017000100133\&script=sci_arttext.

Bittencourt H. B. \& Santos G. L. (2019). Fake news e sua categoria tipológica de violência na contemporaneidade. Diaphora v. 8, n. 2 (2019). Recuperado em: http://dx.doi.org/10.29327/217869.8.2-6.

Bourdieu, P. (2019). A dominação masculina(15ed). Rio de Janeiro: Bertrand Brasil

Brasil (2006). Ministério da Saúde. Secretaria de Atenção à Saúde. Política Nacional de Humanização da Atenção e Gestão do SUS. Clínica ampliada e compartilhada .Brasília: Ministério da Saúde, 64 p. (Série B. Textos Básicos de Saúde). Recuperado em: http://bvsms.saude.gov.br/bvs/publicacoes/ humaniza_sus_atencao_basica.pdf.

Brasil, Lei Maria da Penha. Lei n. 11.340/2006. Coíbe a violência doméstica e familiar contra a mulher. Presidência da República, 2006 Recuperado em: http://www.planalto.gov.br/ccivil_03/_at02004-2006/2006/lei/ 111340.htm.

Broch D; Silva C. D; Acosta D. F; Mattos, M. D; Amarijo, C. L \& Gomes, V. L. de 0. (2017). Representações sociais da violência doméstica contra a mulher entre profissionais de saúde: um estudo comparativo. Revista de Enfermagem do Centro-Oeste Mineiro. Recuperado em: https://doi. org/10.19175/recom.v7i0.1630. 
Castells, M. (1999). 0 poder da identidade São Paulo: Paz e Terra. A era da informação: economia, sociedade e cultura, 2.

Cezario, A, C, F; Fonseca, D S; Lopes, N. C \& Lourenço, L. M. (2015). Violência entre parceiros íntimos: uma comparação dos índices em relacionamentos hétero e homossexuais. Temas em Psicologia, 23(3), 565-575. Recuperado em: https://dx.doi.org/10.9788/TP2015.3-04

d'Oliveira A. F. P. L; Pereira S; Schraiber L. B; Graglia C. G. V; Aguiar J. M; Sousa P. C \& Bonin R. G. (2020). Obstáculos e facilitadores para o cuidado de mulheres em situação de violência doméstica na atenção primária em saúde: uma revisão sistemática. Interface (Botucatu). 24. Recuperado em: https://doi.org/10.1590/Interface.190164.

D’0liveira, A. F. P. L., \& Schraiber, L. B. (2013). Mulheres em situação de violência: entre rotas críticas e redes intersetoriais de atenção. Revista De Medicina, 92(2), 134-140. Recuperado em: https://doi.org/10.11606/ issn.1679-9836.v92i2p134-140.

Foucault, M. (2014). Sobre a história da sexualidade. In: Microfísica do poder (28 ed) São Paulo: Paz \& Terra. p 137-162.

Jacinto, A. M. F. L. (2018). Violência doméstica contra a mulher: representações e práticas do agente comunitário de saúde. Dissertação de Doutorado, Universidade de São Paulo. Recuperado em:https://www.teses.usp.br/ teses/disponiveis/6/6135/tde-15082018-154651/en.php.

Jesus, L. R. de; Sobral, R. de C. C. (2017). Culpabilização da mulher: a perspectiva de policiais de uma delegacia especializada no atendimento à mulher. Revista Ártemis, Vol. XXIII no 1; jan-jun, pp. 196-210.

Lawrenz, P; Macedo, D. M; Hohendorf, J. V; Freitas, C. P. P; Foschiera, L. N. \& Habigzang, L. F. (2018). Violência contra Mulher: Notificações dos Profissionais da Saúde no Rio Grande do Sul. Psicologia: Teoria e Pesquisa, 34. Recuperado em: https://www.scielo.br/scielo.php?pi$\mathrm{d}=$ S0102-37722018000100527\&script=sci_arttext\&tIng=pt.

Martins, A. G. \& Nascimento, A. R. A. (2017). Violência doméstica, álcool e outros fatores associados: uma análise bibliométrica. Arquivos Brasileiros de Psicologia, 69(1), 107-121. Recuperado em: http://pepsic.bvsalud.org/scielo.php?script=sci_arttext\&pi$d=\$ 1809-52672017000100009 \&$ lng $=p t \& t \operatorname{lng}=p t$.

Marques, E. S; Moraes, C. L; Hasselmann, M. H; Deslandes, S. F. \& Reichenheim, M. E. (2020). A violência contra mulheres, crianças e adolescentes em tempos de pandemia pela COVID-19: panorama, motivações e formas de enfrentamento. Cadernos de Saúde Pública, 36(4), Recuperado em: https://doi.org/10.1590/0102-311×00074420.

Minayo, M. C. de S. (1998). A autoviolência, objeto da sociologia e problema de saúde pública: a sociological concern and a public health problem. Cadernos de Saúde Pública, 14(2), 421-428. Recuperado em: https://doi. org/10.1590/S0102-311X1998000200019

Nascimento, V. F; Rosa, T. F. de L; Terças, A. C. P; Hattori, T. Y \& Nascimento, V. F. do. (2019). Desafios no atendimento à casos de violência doméstica contra a mulher em um município matogrossense. Arq. Cienc. Saúde UNIPAR, Umuarama, 23, (1), 15-22. Recuperado em: https://pesquisa.bvsalud. org/portal/resource/pt/biblio-979968.

Organização das Nações Unidas. (2020). Fifa, OMS e União Europeia apoiam campanha de combate à violência doméstica. Notícias da ONU. Recuperado em: https://news.un.org/pt/story/2020/06/1715262.

Pedro, J. M. (2005). Traduzindo o debate: 0 uso da categoria gênero na pesquisa histórica. História (São Paul0), 24(1), 77-98. Recuperado em: https://doi. org/10.1590/S0101-90742005000100004.

Pereira-Gomes, N; Erdmann, A. „ Rebouças-Gomes, N; Silva-Monteiro, D; Santos, R. M. \& Menezes-Couto, T. (2015). Apoio social à mulher em situação de violência conjugal. Revista de Salud Pública, 17(6), 823-835. Recuperado em: https://dx.doi.org/10.15446/rsap.v17n6.36022.

Schraiber, L. B; \& d'Oliveira, A. F. L. P. (1999). Violência contra mulheres: interfaces com a Saúde. Interface - Comunicação, Saúde, Educação, 3(5), 13-26. Recuperado em: https://doi.org/10.1590/S1414-32831999000200003.
Schraiber, L. B; d'Oliveira, A. F. P. L; Portella, A. P. \& Menicucci, E. (2009). Violência de gênero no campo da Saúde Coletiva: conquistas e desafios. Ciência \& Saúde Coletiva, 14(4), 1019-1027. Recuperado em: https://doi. org/10.1590/S1413-81232009000400009.

Santos V. P. C \& Witeck, G. (2016). Violência Doméstica e Familiar Contra a Mulher. XIII Seminário Internacional Demandas Sociais e Políticas Públicas na Sociedade Contemporânea. Recuperado em: https://online.unisc.br/ acadnet/anais/index.php/sidspp/article/view/15858.

Sapkota D; Bhattarai S; Baral D. \& Pokharel, P. K. (2016). Domestic violence and its associated factors among married women of a village development committee of rural Nepal. BMC Res Notes. 2016; 9: 178. Recuperado em: https://www.ncbi.nlm.nih.gov/pmc/articles/PMC4799562/

Vieira, G. 0; Assis, M. M. A; Nascimento, M. A. A; Vieira, T. de 0. \& Netto P. V. (2003). Violência e mortes por causas externas. Revista Brasileira de Enfermagem, 56(1), 48-51. Recuperado em: https://doi.org/10.1590/ S0034-71672003000100010 